\title{
GaN based LNA MMICs for X-Band Applications
}

\author{
Salahuddin Zafar ${ }^{* \# 1}$, Sinan Osmanoglu ${ }^{* \# p 2}$, Mustafa Ozturk ${ }^{\# p 3}$, Busra Cankaya ${ }^{* \# p 4}$, Dogan Yilmaz ${ }^{\# \mathrm{p} 5}$ \\ AhsanUllah Kashif ${ }^{\dagger}$, Ekmel Ozbay ${ }^{* * \mathrm{p} 7}$ \\ *Department of Electrical and Electronics Engineering, I.D. Bilkent University, Turkey \\ \#Nanotechnology Research Center (NANOTAM), Turkey \\ bAselsan Bilkent Micro Nano Technologies (ABMN) Inc. 06800 Ankara, Turkey \\ ${ }^{\dagger}$ Centres of Excellence in Science and Applied Technologies, Islamabad, Pakistan \\ $\left\{{ }^{1}\right.$ salahuddin.zafar, ${ }^{2}$ sinan.osmanoglu, ${ }^{3}$ mozturk, ${ }^{4}$ busra.cankaya, ${ }^{5}$ dogany, ${ }^{7}$ ozbay $\} @$ bilkent.edu.tr, ${ }^{6}$ ahska74@gmail.com
}

\begin{abstract}
In this paper, we report two low noise broadband amplifiers based on ABMN's AlGaN/GaN on SiC HEMT technology for $\mathrm{X}$-band applications. Two design topologies, a single-stage (LNA-1) and a two-stage (LNA-2), have been investigated. LNA-1 and the first stage of LNA-2 is based on common source (CS) with inductive source degeneration topology. LNA-1 has a flat gain response of $\pm 1.4 \mathrm{~dB}$ gain variation with a gain greater than $8 \mathrm{~dB}$ for $9 \mathrm{~V}$ drain voltage and $100 \mathrm{~mA} / \mathrm{mm}$ drain current. Input return loss better than $9.8 \mathrm{~dB}$ and output return loss better than $12.8 \mathrm{~dB}$ have been achieved. The simulated value of noise figure for this design is less than $1.4 \mathrm{~dB}$. In LNA-2 design, a two-stage topology is implemented to enhance amplifier's gain. The simulated values for LNA-2 show a gain greater than $16.8 \mathrm{~dB}$ with $\pm 2.9 \mathrm{~dB}$ gain variation. Input and output return loss values are better than $8.8 \mathrm{~dB}$ and $10 \mathrm{~dB}$, respectively. The value of noise figure for this design is less than $1.7 \mathrm{~dB}$ in the desired frequency range. Both designs, having state-of-the art small dimensions, are suitable for their potential applications for space communications, Radar, satellite communications etc.
\end{abstract}

Keywords - Gallium Nitride; HEMT; broadband; flat gain; LNA; MMIC; X-band; SiC

\section{INTRODUCTION}

Gallium Nitride $(\mathrm{GaN})$ high electron mobility transistor (HEMT) technology has replaced Gallium Arsenide (GaAs) for many applications, specially that are related to high power. GaN is a wideband semiconductor and has a high breakdown electric field. On the other hand, the high saturated drain current density in HEMTs lead to very high channel mobility of electrons. These properties of GaN material and HEMTs make their combination ideal in terms of speed and power at the same time. The bottleneck of low thermal conductivity of GaN material is resolved by growth of $\mathrm{GaN}$ epitaxial layers on silicon carbide (SiC) substrate leading to realization of $\mathrm{GaN} \mathrm{RF}$ power transistors [1], [2].

GaN HEMT technology has emerged as an ideal candidate not only for power but also for low noise amplifiers (LNA). Using the same technology for both transmit and receive MMICs lead to efficient and compact transceiver modules. LNAs based on GaN HEMTs provide built-in capability of handling high power levels at the receiver end, thereby removing the requirement of protection circuitry at the input [2], [3].

There have recently been LNA designs reported in X-band and the performance of LNAs presented in this study are comparable to already published data. Oguz Kazan et. al. have reported a three-stage robust LNA with sub $2 \mathrm{~dB}$ noise figure (NF), more than $20 \mathrm{~dB}$ gain and a gain variation of $\pm 4.8 \mathrm{~dB}$ in the frequency band of $8 \mathrm{GHz}$ to $11 \mathrm{GHz}$ [4]. Bumjin Kim and Weixiang Gao have presented a robust current shared threestage GaN LNA with gain more than $23 \mathrm{~dB}$, gain ripple of $4 \mathrm{~dB}$ and $\mathrm{NF}$ is up to $3 \mathrm{~dB}$ from 8 to $11 \mathrm{GHz}$ [5]. A reconfigurable $\mathrm{S}$ /X-band GaN cascode LNA using $0.15 \mu \mathrm{m}$ GaN on SiC HEMT technology is reported in [6]. The gain ripple is only $1 \mathrm{~dB}$ with overall gain greater than $13.5 \mathrm{~dB}$ for $9-11 \mathrm{GHz}$, which increases to $3.5 \mathrm{~dB}$ for $8-11 \mathrm{GHz}$ with reduction of gain to $11 \mathrm{~dB}$. Woojin Chang et. al. have demonstrated a compact X-band LNA with decent gain and noise figure at the cost of input return loss (IRL) and output return loss (ORL) [7]. Overall performance of presented LNAs show promising results in terms of return losses, gain ripple and NF as compared to already state-of-the art reported data.

In our study, we designed LNAs with the goal of promising IRL and ORL values, low NF and decent in-band gain along with minimum gain ripple from $8 \mathrm{GHz}$ to $11 \mathrm{GHz}$. Common source (CS) topology with inductive source degeneration is employed for both designs. The combination of common source with inductive source degeneration ensures good linearity and better noise performance $[3,8]$. The transistor characterization, design and fabrication for LNA-1 is performed using $0.15 \mu \mathrm{m}$ AlGaN/GaN HEMT on SiC process of Aselsan Bilkent Micro Nano Technologies Inc. (ABMN). The characterization and fabrication of LNA-2 MMIC is not finished, hence only simulated results of LNA-2 are shared in this paper.

\section{FABRICATION PROCESS}

ABMN's in-house microstrip AlGAN/GaN HEMT on SiC technology is used to fabricate the presented LNA MMICs. Epitaxial growth is performed by metal-organic chemical vapor deposition (MOCVD) on a 3-inch $\mathrm{SiC}$ substrate.

The active device fabrication starts with non-alloyed ohmic contacts, which have $0.15-0.25 \mathrm{Ohm} . \mathrm{mm}$ contact resistance. Mesa isolation is performed in $\mathrm{Cl}_{2} / \mathrm{Ar}$ plasma with an inductively coupled plasma (ICP)-RIE system. Electron beam lithography is used to form the gates of the devices. ABMN's $0.15 \mu \mathrm{m}$ gate technology is implemented for this design. $\mathrm{Si}_{\mathrm{x}} \mathrm{N}_{\mathrm{y}}$ layers are applied by plasma-enhanced chemical vapor deposition (PECVD) for passivation and to form $250 \mathrm{pF} / \mathrm{mm} 2$ metal-insulator-metal (MIM) capacitors. Thin-film resistors (TFR) with $30 \Omega / \square$ are formed using TaN thin film layer. 
Substrate vias are used to connect the bottom ground plane to front side.

\section{BROADBAND LNA DESIGN}

The schematics of LNA-1 and LNA-2 designs are shown in Fig. 1. The stability networks in both designs are of the same technique and designed at the output side of the transistor for better noise performance. These stability networks for both designs also provide the drain bias lines. For LNA-1, input matching network (IMN) serves the purpose of providing the gate bias along with matching for low NF and IRL.

For LNA-2 both stages have common source (CS) topology with inductive source degeneration for first stage only. IMN of the first stage is designed for achieving minimum NF along with having the gate bias network. Output matching network is designed to maximize the gain. Inter-stage matching network provides the minimum gain ripple in the band with an added function of gate bias for the second stage.

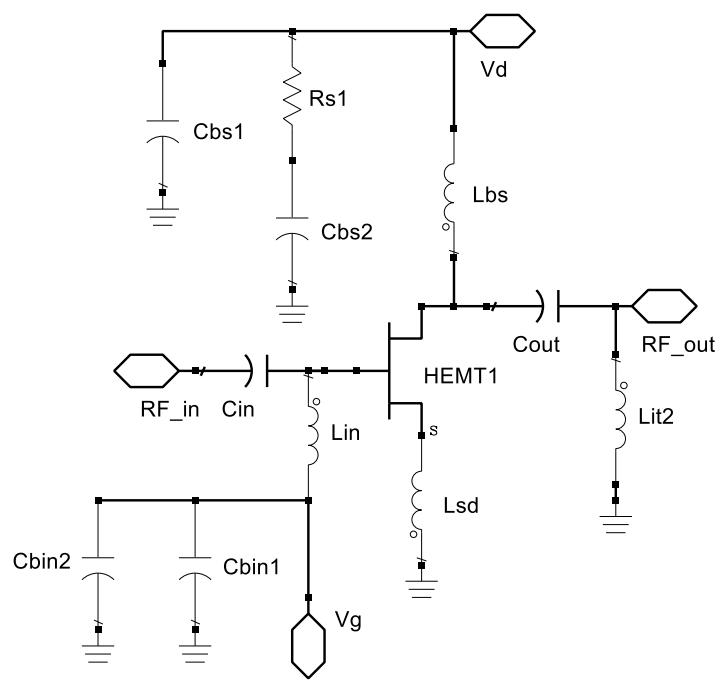

Fig. 1a. Schematic of GaN HEMT LNA-1

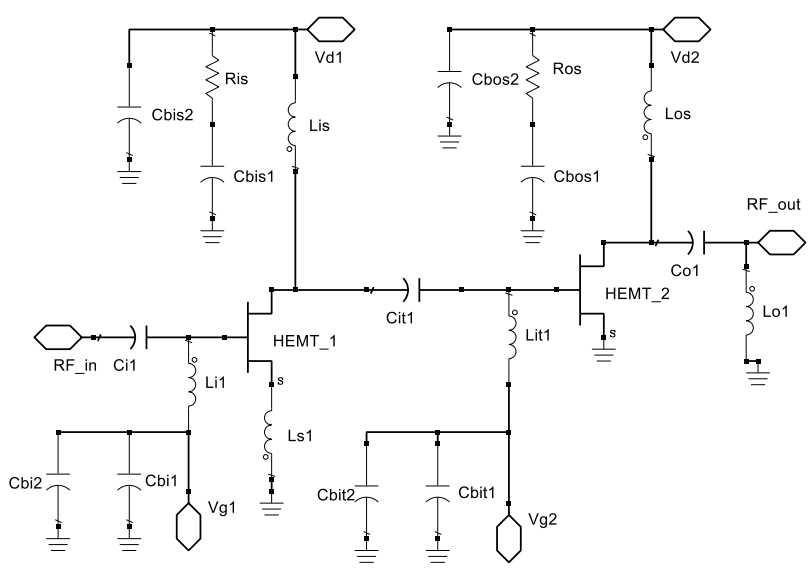

Fig. 1b. Schematic of GaN HEMT LNA-2

\section{RESUlTS AND DiscUSSION}

Fig. 2a shows the photograph of fabricated broadband LNA1 and Fig. $2 b$ shows the layout of our proposed broadband LNA-2. The size of LNA-1 MMIC is $1.8 \mathrm{~mm} \times 2 \mathrm{~mm}$ while that of LNA-2 is $2.8 \mathrm{~mm} \times 2.3 \mathrm{~mm}$.

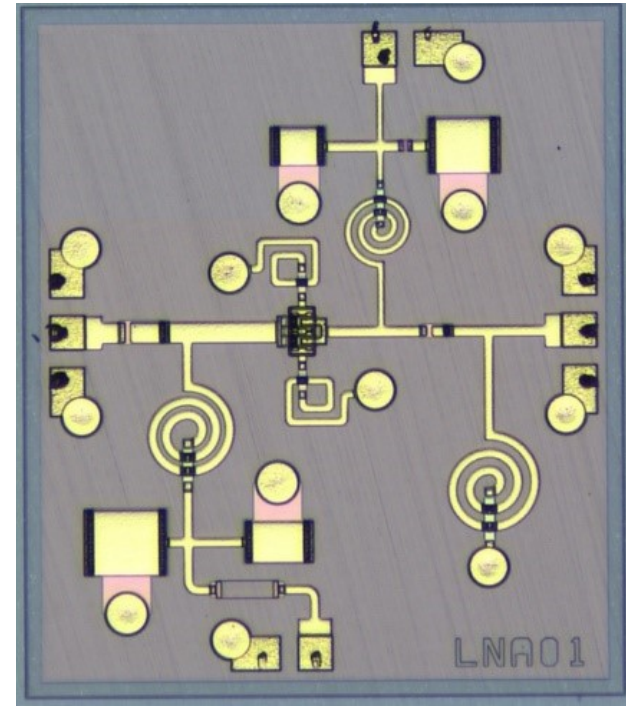

Fig. 2a. Photograph of fabricated LNA-1 MMIC

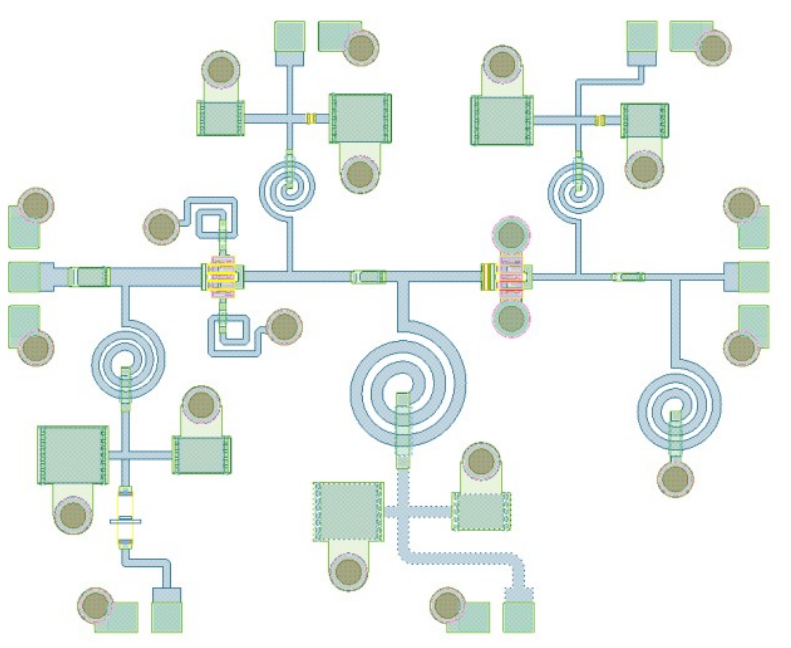

Fig. 2b. Layout of LNA-2 MMIC

Electromagnetic (EM) simulations for LNA-1 resulted in flat gain more than $8 \mathrm{~dB}$ with a gain variation of $\pm 1.4 \mathrm{~dB}$ from $8 \mathrm{GHz}$ to $11 \mathrm{GHz}$. IRL and ORL are better than $10.7 \mathrm{~dB}$ and $12.2 \mathrm{~dB}$ respectively. Stability is sustained for the entire desired frequency range. Fig. 3 shows simulated and measured Sparameter results of LNA-1. The fabricated device has a gain greater than $8 \mathrm{~dB}$ with $2.8 \mathrm{~dB}$ ripple. IRL and ORL are better than $9.8 \mathrm{~dB}$ and $13.1 \mathrm{~dB}$, respectively. Measurement results show a perfect match with the simulated results. Fig. 4 shows that the simulated NF of LNA-1 is less than $1.4 \mathrm{~dB}$, for which the measurements have not performed yet. 


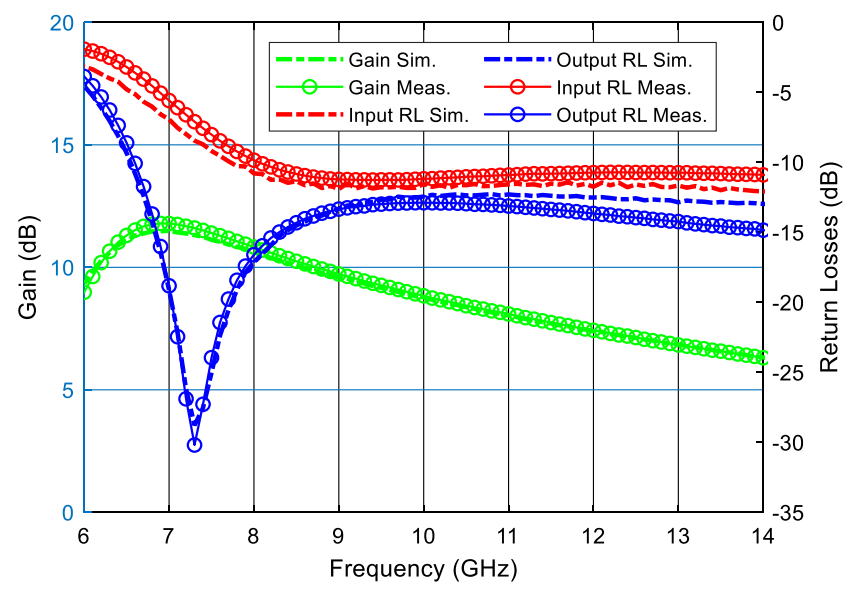

Fig. 3. S-parameters measurement results of fabricated LNA-1 at bias of 10 $\mathrm{V}, 100 \mathrm{~mA} / \mathrm{mm}$ along with the simulation results

Analysis of the fabricated LNA-1 is also performed at different bias points as shown in Fig. 5. It is observed that the device performs better in terms of return losses and gain at higher bias drain currents. The maximum gain is achieved at the lower frequency of the desired band $(10.8 \mathrm{~dB}$ at $8 \mathrm{GHz})$. While due to gain roll-off by change in the frequency, a lower gain around $8 \mathrm{~dB}$ is achieved at $11 \mathrm{GHz}$. Hence, typical gain of 8.7 $\mathrm{dB}$ is achieved at $9.5 \mathrm{GHz}$. Therefore, a gain variation of \pm 1.4 $\mathrm{dB}$ is achieved at the desired band. The gain is dropped to 10.5 $\mathrm{dB}$ at $8 \mathrm{GHz}$ and $7.7 \mathrm{~dB}$ at $11 \mathrm{GHz}$ when the drain bias point is reduced from $10 \mathrm{~V}, 100 \mathrm{~mA} / \mathrm{mm}$ to $10 \mathrm{~V}, 75 \mathrm{~mA} / \mathrm{mm}$. Similar drop is observed for further reduction of drain bias to $10 \mathrm{~V}, 50$ $\mathrm{mA} / \mathrm{mm}$, but the gain ripple remains to be the same for all the cases. IRL is degraded with the reduction in the drain bias current but it is better than $8 \mathrm{~dB}$ for all bias points. ORL is smaller than $11.5 \mathrm{~dB}$ for any bias condition. The LNA-1 MMIC gives promising results for all three bias conditions, having the best results for higher drain bias current.

Large signal of LNA-1 is measured to observe the output power at 1-dB compression point $(\mathrm{P} 1 \mathrm{~dB})$ in the desired frequency band, which is shown in Fig. 6. It ranges from 17 $\mathrm{dBm}$ to $19 \mathrm{dBm}$ for $8 \mathrm{GHz}$ to $11 \mathrm{GHz}$ frequency range.

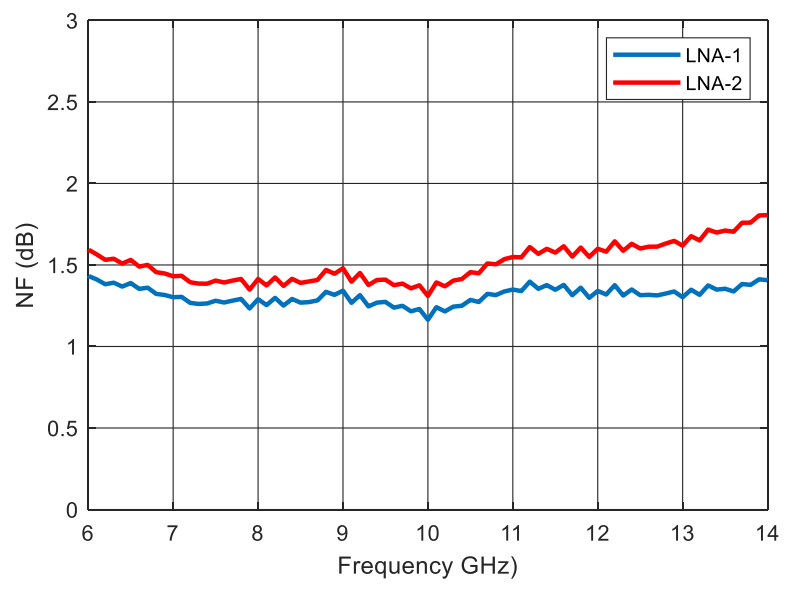

Fig. 4. Noise figure simulation results of LNA-1 and LNA-2

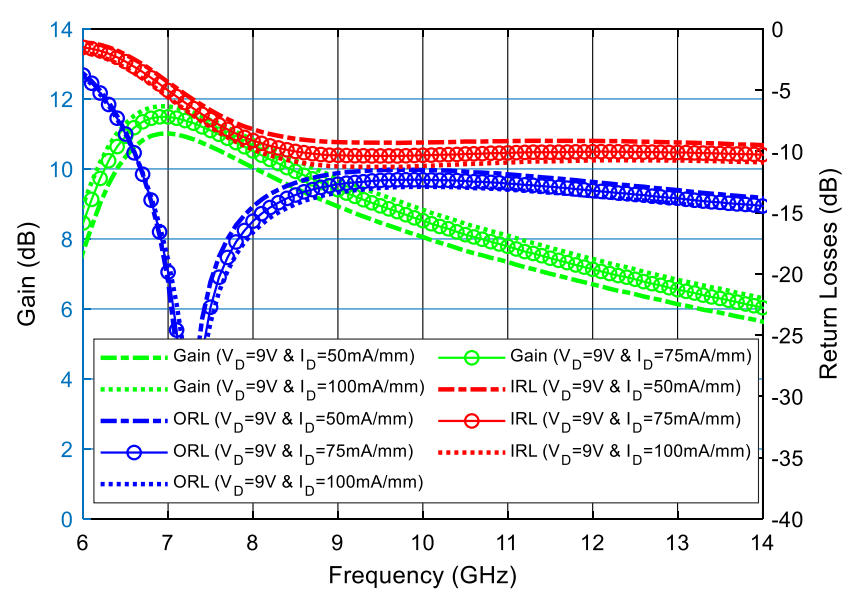

Fig. 5. S-parameters data of different bias points for LNA-1

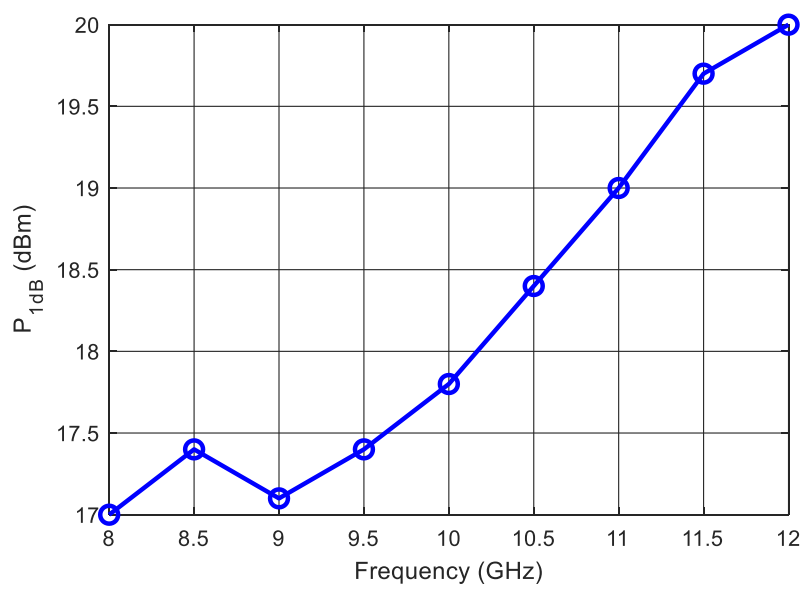

Fig. 6. P1dB vs Frequency for LNA-1

Fig. 4 and Fig. 7 demonstrate the EM simulation results of NF and S-parameters for LNA-2. Overall gain better than 16.8 $\mathrm{dB}$ with a variation of $\pm 2.9 \mathrm{~dB}$ is achieved. LNA-2 gives IRL and ORL better than $8.8 \mathrm{~dB}$ and $10 \mathrm{~dB}$, respectively. Simulated $\mathrm{NF}$ for the whole band from $8-11 \mathrm{GHz}$ is less than $1.7 \mathrm{~dB}$.

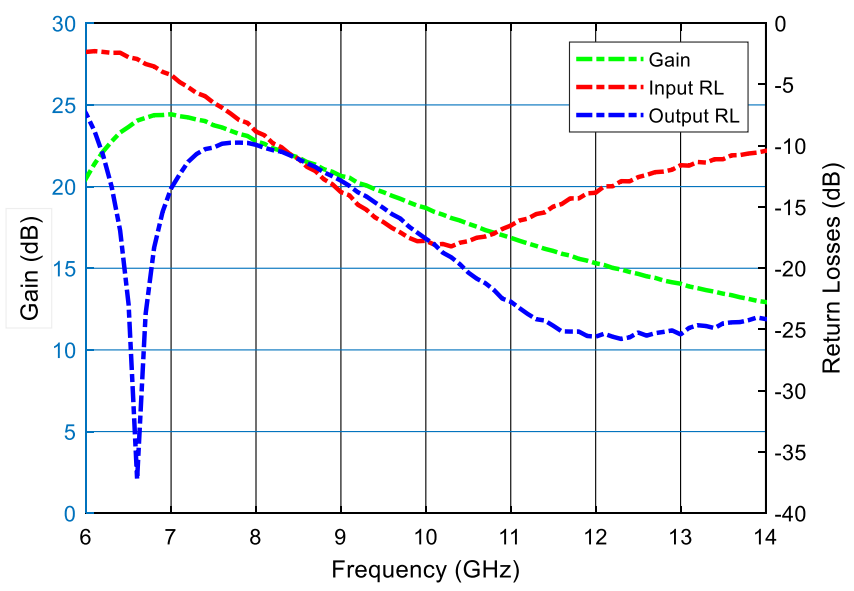

Fig. 7. S-parameters simulation results of LNA-2 
Table 1. Comparative analysis with recently published data ( ${ }^{+}$Estimated values from figure, ${ }^{*}$ Simulated, $\mathrm{CS}=\mathrm{Common}$ Source, $\left.\mathrm{FB}=\mathrm{Feedback}\right)$

\begin{tabular}{|c|c|c|c|c|c|c|c|c|c|}
\hline Ref. & Freq. & $\begin{array}{l}\text { IRL } \\
\text { (dB) }\end{array}$ & $\begin{array}{l}\text { ORL } \\
\text { (dB) }\end{array}$ & $\begin{array}{l}\text { Gain } \\
\text { (dB) }\end{array}$ & NF (dB) & \begin{tabular}{|c|} 
Gain \\
Variation (dB) \\
\end{tabular} & Process & Technique & \begin{tabular}{|c|} 
Chip Size \\
$(\mathbf{m m}$ X mm)
\end{tabular} \\
\hline$[4]$ & $8-11 \mathrm{GHz}$ & $<-9.1$ & $<-6^{+}$ & $>22$ & $<2$ & \pm 4.4 & $\begin{array}{c}0.25 \mu \mathrm{m} \mathrm{GaN} / \mathrm{SiC} \\
\mathrm{HEMT}\end{array}$ & $\begin{array}{l}\text { CS with series } \\
\text { inductive source } \\
\text { degeneration and } \\
R C \text { FB (3-satge) }\end{array}$ & $2.8 \times 1.3$ \\
\hline$[5]$ & $8-11 \mathrm{GHz}$ & $<-6^{+}$ & $<-10^{+}$ & $>23^{+}$ & $<3^{+}$ & $\pm 2^{+}$ & $0.25 \mathrm{GaN} / \mathrm{SiC}$ HEMT & $\begin{array}{c}\text { CS with source } \\
\text { degeneration (3-stage) }\end{array}$ & $2.72 \times 1.16$ \\
\hline [6] & $\begin{array}{l}9-11 \mathrm{GHz} \\
8-11 \mathrm{GHz} \\
\end{array}$ & $<-11$ & $<-4^{+}$ & $\begin{array}{l}>13.5 \\
>11\end{array}$ & $<2.2$ & $\begin{array}{c} \pm 0.5 \\
\pm 1.75^{+} \\
\end{array}$ & $\begin{array}{c}0.15 \mu \mathrm{m} \mathrm{GaN} / \mathrm{SiC} \\
\mathrm{HEMT}\end{array}$ & Cascode & - \\
\hline [7] & $\begin{array}{c}9.7-12.9 \\
\mathrm{GHz}\end{array}$ & $<-2$ & $<-6$ & $>20$ & $<2.1$ & \pm 3 & $\begin{array}{c}0.25 \mu \mathrm{m} \mathrm{GaN} / \mathrm{SiC} \\
\text { HEMT }\end{array}$ & Two-stage & $1.7 \times 0.8$ \\
\hline LNA-1 & $8-11 \mathrm{GHz}$ & $<-9.8$ & $<-12.8$ & $>8$ & $<1.4^{*}$ & \pm 1.4 & $\begin{array}{c}0.15 \mu \mathrm{m} \text { AlGaN / GaN } \\
\text { HEMT }\end{array}$ & $\begin{array}{c}\text { CS with inductive source } \\
\text { degeneration }\end{array}$ & $1.8 \times 2$ \\
\hline LNA-2* & $8-11 \mathrm{GHz}$ & $<-8.8$ & $<-10$ & $>16.8$ & $<1.7$ & \pm 2.9 & $\begin{array}{c}0.15 \mu \mathrm{m} \text { AlGaN / GaN } \\
\text { HEMT }\end{array}$ & $\begin{array}{l}\text { CS with inductive source } \\
\text { degeneration }\left(1^{\text {st }} \text { stage }\right)\end{array}$ & $2.8 \times 2.3$ \\
\hline
\end{tabular}

Comparative analysis of our proposed LNAs with already published data is summarized in Table-1. Both LNA-1 and LNA-2 are better in terms of IRL and ORL parameters. Those reported results with high gain than our LNAs are either 3 -stage or have high gain ripple. The proposed LNAs in this study have not only promising NF but also a decent gain and reduced gain ripple. The small MMIC area of both LNAs make them ideal candidate for Radar and wireless communication applications in X-band.

\section{CONCLUSION}

Two broadband common source LNAs are presented in this work. The characterization and design of both LNA MMICs are performed using ABMN's $0.15 \mu \mathrm{m}$ GaN HEMT technology. Measurements for the fabricated LNA-1 show a flat gain with $\pm 1.4 \mathrm{~dB}$ variation and a NF less than $1.4 \mathrm{~dB}$ along with promising IRL and ORL values.

The fabrication of LNA-2 MMIC is on-going, therefore only EM simulations results are presented here. These results show exceptional performance parameters in terms of gain, NF and return losses. The match between simulated and measured results for LNA-1 gives a confidence to expect the desired measurement results for LNA-2 after fabrication. The focus of future two-stage design is to further improve the gain and its ripple without compromising the noise performance.

\section{ACKNOWLEDGMENT}

The authors are indebted to ABMN fabrication and measurement teams for their workmanship and efforts in the fabrication and measurements of the devices and MMICs.

\section{REFERENCES}

[1] M. Rudolph, "GaN HEMTs for low-noise amplification - status and challenges," 2017 Integrated Nonlinear Microwave and Millimetrewave Circuits Workshop (INMMiC), Graz, 2017, pp. 1-4.

[2] R. Caverly et al., "Advancements at the Lower End: Advances in HF, $\mathrm{VHF}$, and UHF Systems and Technology," in IEEE Microwave Magazine, vol. 16, no. 1, pp. 28-49, Feb. 2015.

[3] K.W. Kobayashi, Mike Wojtowicz (2012). "GaN Low Noise Broadband Amplifiers and Technology". [Online]. Available: http://citeseerx.ist.psu.edu/viewdoc/download?doi=10.1.1.364.6164\&re $\mathrm{p}=$ rep1\&type $=$ pdf [Oct. 13, 2019].

[4] O. Kazan, F. Kocer and O. A. Civi, "An X-Band Robust GaN Low-Noise Amplifier MMIC with Sub 2 dB Noise Figure," 2018 48th European Microwave Conference (EuMC), Madrid, 2018, pp. 1202-1204.

[5] B. Kim and W. Gao, "X-Band Robust Current-Shared GaN Low Noise Amplifier for Receiver Applications," 2016 IEEE Compound Semiconductor Integrated Circuit Symposium (CSICS), Austin, TX, 2016,pp.1-4.

[6] K. W. Kobayashi, C. Campbell, C. Lee, J. Gallagher, J. Shust and A Botelho, "A reconfigurable S-/X-band GaN cascode LNA MMIC," 2017 IEEE Compound Semiconductor Integrated Circuit Symposium (CSICS), Miami,FL,2017,pp.1-4.

[7] W. Chang, G. Jeon, Y. Park, S. Lee and J. Mun, "X-band low noise amplifier MMIC using $\mathrm{AlGaN} / \mathrm{GaN}$ HEMT technology on $\mathrm{SiC}$ substrate," 2013 Asia-Pacific Microwave Conference Proceedings (APMC), Seoul, 2013, pp. 681-684.

[8] K. W. Kobayashi, Y. Chen, I. Smorchkova, R. Tsai, M. Wojtowicz and A. Oki, "A 2 Watt, Sub-dB Noise Figure GaN MMIC LNA-PA Amplifier with Multi-octave Bandwidth from 0.2-8 GHz," 2007 IEEE/MTT-S International Microwave Symposium, Honolulu, HI, 2007, pp.619-622. 